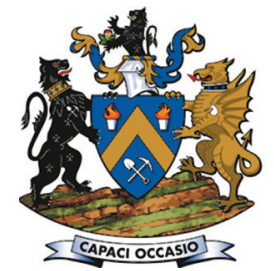

Affiliation:

${ }^{1}$ Council for Scientific

and Industrial Research,

Manufacturing Cluster, Advanced

Materials Engineering, Meiring

Naude Road, P O Box, 395,

Pretoria, South Africa.

2Department of Materials Science

and Metallurgical Engineering,

Faculty of Engineering, Built

Environment and Information

Technology, University of

Pretoria, South Africa.

Correspondence to:

M.N. Mathabathe

Email:

nmathabathe@csir.co.za

Dates:

Received: 30 Aug. 2020

Revised: 26 Mar. 2021

Accepted: 1 Apr. 2021

Published: April 2021

\section{How to cite:}

Mathabathe, M.N., Bolokang,

A.S., Govender, G., Siyasiya,

C.W., and Mostert, R.J. 2021

Deformation and fracture

behaviour of the $\gamma$-TiAl based

intermetallic alloys.

Journal of the Southern African

Institute of Mining and Metallurgy,

vol. 121, no. 4, pp. 169-174.

DOI ID:

http://dx.doi.org/10.17159/2411-

9717/1344/2021

ORCID

M.N. Mathabathe

https://orchid.org/0000-0001-

7058-5647

\title{
Deformation and fracture behaviour of the $\gamma$-TiAl based intermetallic alloys
}

\author{
M.N. Mathabathe',2, A.S. Bolokang ${ }^{1}$, G. Govender ${ }^{1}$, C.W. Siyasiya ${ }^{2}$, \\ and R.J. Mostert ${ }^{2}$
}

\section{Synopsis}

The $\beta$-solidifying $\gamma$-TiAl intermetallic alloys of nominal composition Ti-48Al (binary alloy), Ti-48Al-2Nb (ternary alloy), Ti-48Al-2Nb-0.7 Cr (quaternary alloy), and Ti-48Al-2Nb-0.7Cr-0.3Si (quinary alloy) (in at.\%) were developed. The materials produced were tensile tested at room temperature. The as-cast microstructures and fracture surfaces of the tensile tested specimens were examined using conventional metallographic methods. Microstructural examination indicated that the alloys were comprised of lamellar structures $\left(\alpha_{2}+\gamma\right)$ embedded in columnar dendritic cores in the as-cast condition. However, the quinary alloy contained $\mathrm{a} \mathrm{Ti}_{5} \mathrm{Si}_{3}$ second phase. The alloys exhibited no detectable ductility during tensile deformation, indicating the brittleness of all the materials. The fracture surfaces revealed that the alloys failed by translamellar fracture with correspondingly few cleavage facets.

\section{Keywords}

$\gamma$-TiAl based alloys, $\beta$-solidifying, translamellar fracture.

\section{Introduction}

The advent of high-temperature materials with potential use as structural materials, shape memory alloys, and coatings is of significance for a range of applications. Single-crystal nickel-based superalloys are the most successful gas turbine materials as a result of their good mechanical properties at elevated temperature imparted by the $\gamma^{\prime}-\mathrm{Ni}_{3} \mathrm{Al}\left(\mathrm{L1}_{2}\right)$ phase in the fcc matrix (Liu et al., 2017). The $\gamma$-TiAl intermetallic alloys are competitive materials for elevated temperature applications, mainly because of reduced density, high specific strength, and modulus (Mathabathe et al., 2018a, 2018b). The commercialization of $\gamma$-TiAl intermetallic alloys depends on microstructure and texture control by thermomechanical processing techniques (Mathabathe et al., 2019b).

Research interest in titanium aluminides was stimulated due to their outstanding combination of high melting temperature and low density with desirable medium/high temperature mechanical properties and notable corrosion and oxidation resistance. These properties made the $\alpha_{2} / \gamma$-based titanium aluminides suitable for application in many fields (Grytsiv et al., 2005; Kumaran et al., 2008). These intermetallic ordered compounds are stiffer, lighter, and have better mechanical properties than conventional titanium alloys, with relatively low ambient-temperature tensile strength (Lipsitt, Shechtman, and Schafrik, 1980). Yan et al. (2009) reported that the TiAl-based alloys have a higher chemical reactivity, larger solidification shrinkage rate, and lower castability than typical Al casting alloys. This can cause misrun defects on the surface of the components, but also results in shrinkage porosity and cracking defects due to poor ductility. Therefore, further alloying of TiAl alloys made sense as this served to enhance the mechanical properties.

Lipsitt, Shechtman, and Schafrik (1980) studied the stoichiometric behaviour of intermetallic compounds in TiAl alloys to ascertain the potential for enhancing the ductility-temperature relationship. The study reported on the tensile and fracture properties over a wide temperature range. The results showed a significant relationship between dislocation structures, fracture modes, and tensile properties at each temperature. In our previous study (Mathabathe et al., 2018b) the effects of alloying elements on the grain size and macrohardness were demonstrated. The study indicated that the addition of $\mathrm{Nb}$ and $\mathrm{Cr}$ played an important role in decreasing the grain size of the ternary and quaternary alloys. The binary alloy had the largest grain size of $280 \mu \mathrm{m}$, while alloying TiAl with 2 at.\% $\mathrm{Nb}$ reduced the grain size in the ternary alloy to $180 \mu \mathrm{m}$. Elements such as $\mathrm{Nb}$ are known to act as $\beta$-phase stabilizers in Ti; however, in TiAl alloy $\mathrm{Nb}$ plays two roles - it reduces the grain size and stabilizes the $\beta$-phase. Addition of $\mathrm{Cr}$ improved the grain refinement further, leading to a quaternary alloy. In the quinary alloy the grain size slightly increases due to the addition of Si, implying that the ductility of the alloy was enhanced following the Hall Petch relationship (Chen et al., 2004). 


\section{Deformation and fracture behaviour of the $\gamma$-TiAl based intermetallic alloys}

The tensile properties of the alloys were similar to those reported by Mathabathe et al., (2018b), with changes effected by the alloying elements. The addition of $\mathrm{Nb}$ to binary TiAl slightly increased the tensile strength. However, the quaternary alloy showed the lowest tensile strength, due to alloying with Cr. Super-dislocation and twin nucleation are often competing mechanism in $\gamma$-TiAl alloys, due to stacking fault energy (Huang and Hall, 1991). Duplex structures favour twin deformation as a result of the lower fault energy due to the presence of $\alpha_{2}$ and/or lower $\mathrm{Al}$ concentration with the ability to absorb and reduce the interstitial content in the $\gamma$-phase (Liu et al., 2016).

Therefore, in the current study we investigated the deformation behaviour of the previously studied $\gamma$-TiAl-based alloys (Mathabate et al., 2018b), where the microstructure and fracture analysis after tensile testing are discussed. Moreover, the study aims to ascertain the effect of $\beta$-phase on room temperature ductility, whereby the tensile fracture is evaluated.

\section{Experimental}

Pure metallic powders of $\mathrm{Ti}, \mathrm{Al}, \mathrm{Nb}, \mathrm{Cr}$, and $\mathrm{Si}$ were mixed together to give nominal compositions of Ti-48Al, Ti-48Al-2Nb, Ti-48Al-2Nb-0.7Cr, and Ti-48Al-2Nb-0.7Cr-0.7Si (in atomic percentage, at.\%). These compositions were consolidated and compacted prior to vacuum arc melting. The fabrication method was adapted from Mathabathe et al. (2019a). Conventional metallographic preparation techniques were used to prepare the samples. Optical microscopy and scanning electron microscopy
(SEM), using a JEOL ${ }^{\circledR}$ JSM-6510 equipped with backscattered electron (BSE) mode and energy-dispersive X-ray spectroscopy (EDS) were used to investigate the microstructures. The EDS analysis position had a working distance (WD) of $10 \mathrm{~mm}$ and a take-off angle of $35^{\circ}$ for X-ray signals was utilized, with efficient mapping analysis under secondary electron imaging (SEI) observation. The acceleration voltage employed was $20 \mathrm{kV}$ (Mathabathe et al., 2018b). The morphologies of the fracture surfaces, as well as electropolished longitudinal sections of the tensile specimens, were investigated using SEM-SEI (secondary electron imaging). Room-temperature tensile tests using an MTS criterion C45 tensile machine were conducted on flat tensile specimens of dimensions $5 \mathrm{~mm} \times 3 \mathrm{~mm}$ cross-section and $12 \mathrm{~mm}$ gauge length, using a constant crosshead speed of $0.25 \mathrm{~mm} / \mathrm{min}$.

\section{Results and discussion}

\section{Microstructure analysis}

Figure 1 shows the optical microstructures of the binary, ternary, quaternary, and quinary alloys. The microstructures in Figures $1 \mathrm{a}, 1 \mathrm{~b}$, and $1 \mathrm{c}$ are comprised of the light network primary $\beta$-phase, while the dark features are $\gamma$-phase. Due to the addition of $\mathrm{Si}$, the sample in Figure 1d shows the light phase as quinary alloy due to the presence of titanium silicate precipitate $\left(\mathrm{Ti}_{5} \mathrm{Si}_{3}\right)$. The $\beta$-grains are irregular in shape, as well as the fine $\gamma$-grains along the grain boundaries. The microsegregation of $\beta$-stabilizers $\mathrm{Nb}$ and $\mathrm{Cr}$ on the dendritic cores possibly formed as a result of
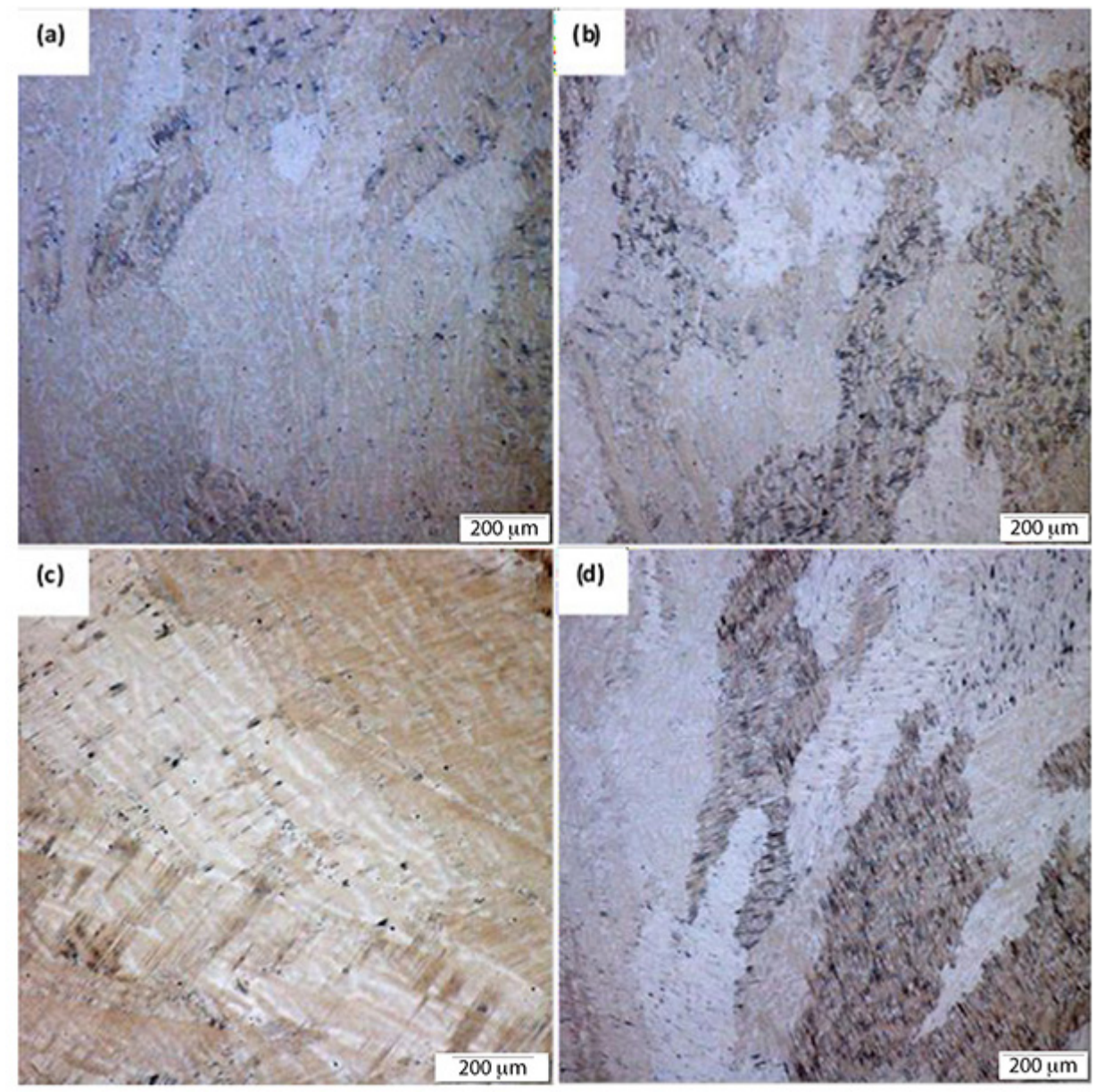

Figure 1-Optical images of the (a) binary (Ti-48Al), (b) ternary (Ti-48Al-2Nb), (c) quaternary (Ti-48Al-2Nb-0.7Cr), and (d) quinary (Ti-48Al-2Nb-0.7Cr-0.3Si) alloys 


\section{Deformation and fracture behaviour of the $\gamma$-TiAl based intermetallic alloys}

solidification, while few retained primary $\beta$-phases were observed after cooling due to enrichment in $\beta$-phase stabilizers (Wang et al., 2011).

The SEM images of the binary, ternary, quaternary and quinary alloys are shown in Figure. 2. Figure 2a shows the microstructure of binary TiAl, comprised of the lamellar structure $\left(\alpha_{2}+\gamma\right)$. The corresponding chemical compositions of the lamellar structure of the binary, ternary, quaternary, and quinary alloys are presented is Table I. The lamellar colonies are evident, while the $\beta$-phase was segregated along the grain boundaries of the $\gamma$-phase. Figures $2 b-d$ confirm that the lamellar colonies appear finer in the alloys containing $\mathrm{Nb}, \mathrm{Cr}$, and $\mathrm{Si}$.

It is important to note that the $\mathrm{Cr}$ atoms occupy Ti-sites in a single $\gamma$-phase alloy, resulting in a small Ti-Al bond adjustment and increased plasticity (Liu et al., 2016). However, when $\mathrm{Cr}$ atoms occupy the $\mathrm{Al}$ sites in a duplex alloy, the overall covalency of the Ti-Al bond is lowered and plastic deformation is favoured, decreasing the ultimate tensile strength in the quaternary alloy. Furthermore, Si addition drastically increased the tensile strength of the quinary alloy. The improved properties in the quinary alloy indicate that the addition of Si to the TiAl-based alloy promoted the room temperature ductility due to $\mathrm{Ti}_{5} \mathrm{Si}_{3}$ whisker formation during solidification (Sun and Froes, 2002). The interface between the matrix and strip/rod-like $\mathrm{Ti}_{5} \mathrm{Si}_{3}$ particles retards the motion of dislocations, thus increasing the strength (Liu et al., 2016).

\section{Fracture behaviour}

The SEM secondary electron (SE) mode images of the fracture surface after room temperature tensile tests are shown in Figure 3. A mixture of grain boundary and transgranular fracture for the binary alloy is shown in Figure 3a. The duplex structure $\left(\alpha_{2}+\gamma\right)$ underwent cleavage or lamellar interface failure. Figures $3 \mathrm{a}-\mathrm{-c}$ illustrate fracture surfaces with a slightly rough appearance and irregular arrangement. The planar regions are illustrated by the arrows. The addition of $\mathrm{Cr}$ increased the probability of intragranular failure in the duplex structure (Huang and Hall, 1991). The quinary alloy (Figure 3d) shows the flattest/rough fractured surface discontinuities. The twinning and glide at ambient temperature arise effortlessly in grains that are globular due to fewer deformation obstacles present. The dislocation movements are hindered by a variety of interfaces (short-range) resulting in limited overall deformation (Kabir et al., 2015).

Figures $4 \mathrm{a}$ and $4 \mathrm{~b}$ illustrate the fracture surfaces of the binary and quaternary alloys with the emphasis on showing the facets. These two alloys exhibited the lowest tensile strength
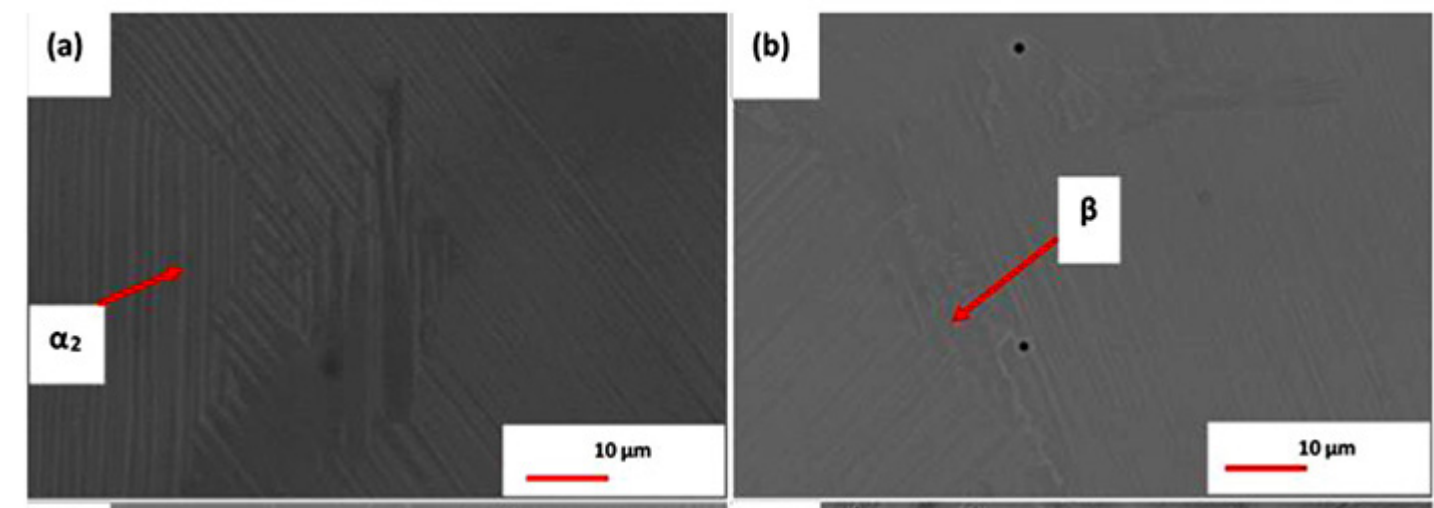

\section{(c)}

(d)

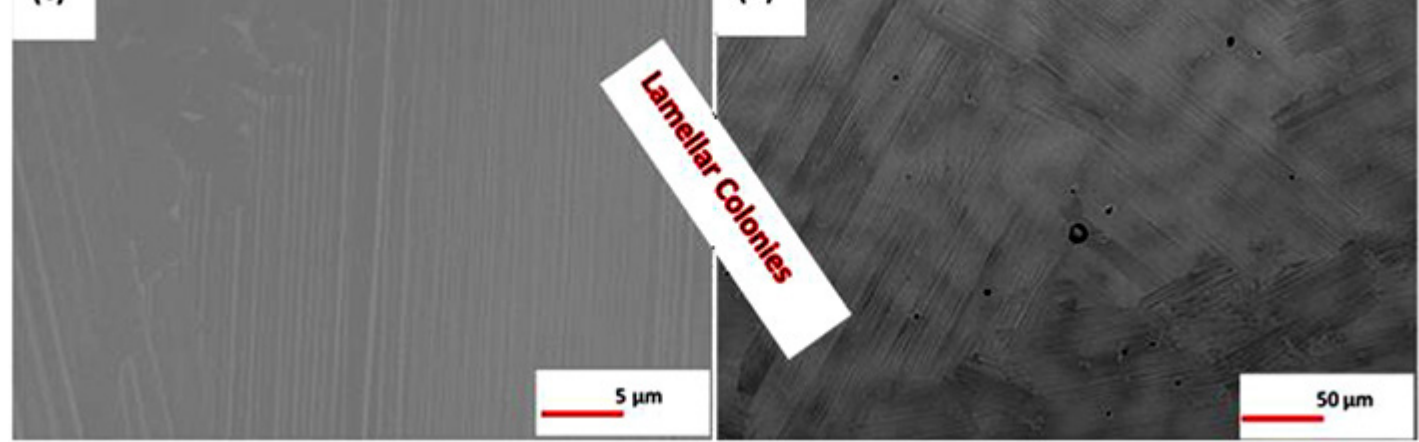

Figure 2-SEM/BSE images of the (a) binary (Ti-48Al), (b) ternary (Ti-48Al-2Nb), (c) quaternary (Ti-48Al-2Nb-0.7Cr), and (d) quinary (Ti-48Al-2Nb-0.7Cr-0.3Si) alloys

Table I

EDS chemical composition of the lamellar structure of the Ti-48Al, Ti-48Al-2Nb, Ti-48Al-2Nb-0.7Cr and Ti-48Al-2Nb0.7 Cr-0.3Si alloys

\begin{tabular}{|l|c|c|c|c|}
\hline Alloy & Ti & Al & Nb & Cr \\
\hline Binary & $57.13 \pm 1.58$ & $42.87 \pm 0.73$ & - & - \\
Ternary & $48.87 \pm 0.46$ & $49.42 \pm 1.59$ & $1.70 \pm 0.81$ & - \\
Quaternary & $49.45 \pm 0.89$ & $49.45 \pm 0.34$ & $1.94 \pm 1.19$ & - \\
Quinary & $49.39 \pm 1.28$ & $49.39 \pm 1.28$ & $1.72 \pm 1.30$ & $0.75 \pm 0.25$ \\
\hline
\end{tabular}


Deformation and fracture behaviour of the $\gamma$-TiAl based intermetallic alloys
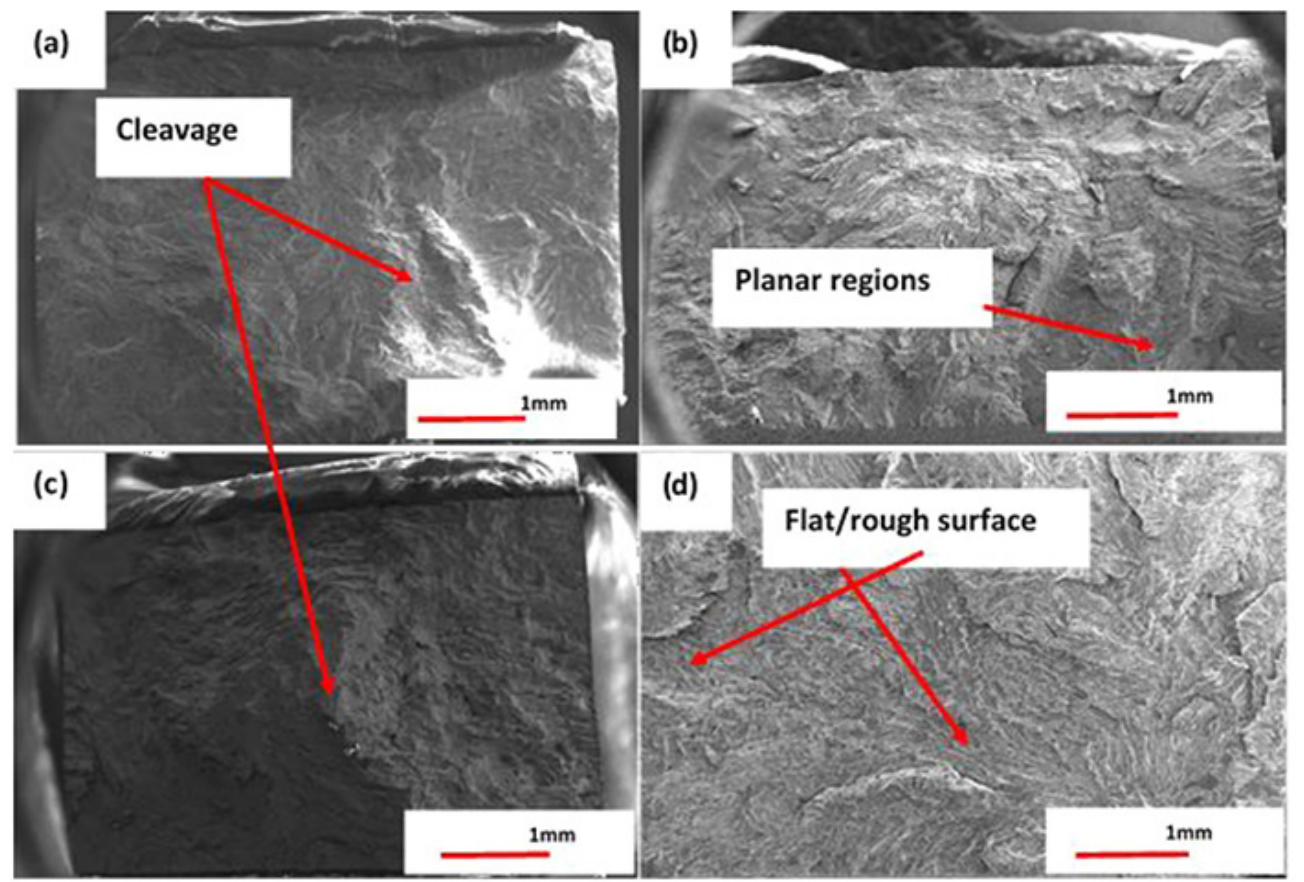

Figure 3-Fracture surfaces after tensile testing of the (a) Ti-48Al, (b) Ti-48Al-2Nb, (c) Ti-48Al-2Nb-0.7Cr), and (d) Ti-48Al-2Nb-0.7Cr-0.3Si alloys
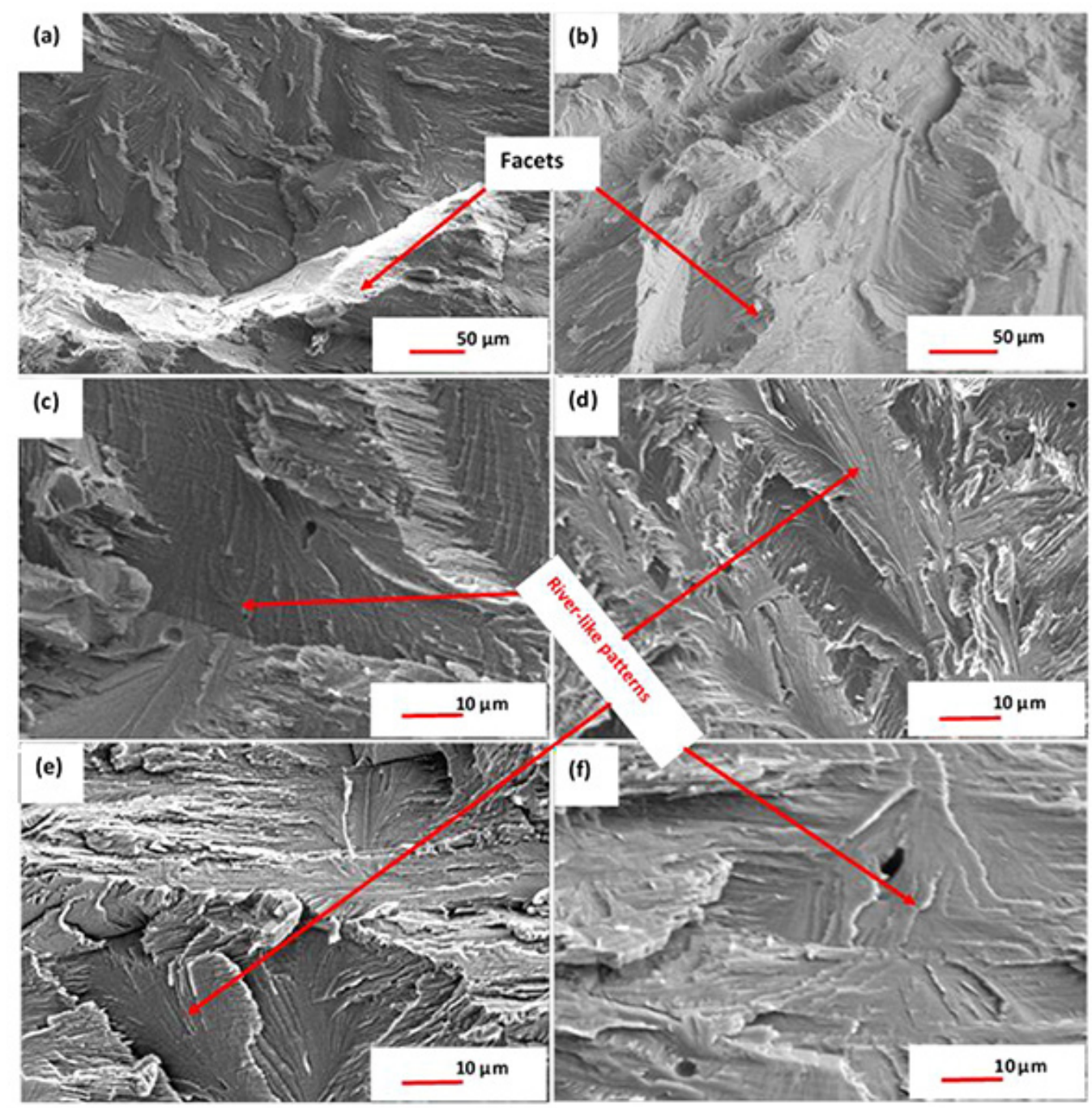

Figure 4-Fracture surfaces showing facets on the low tensile strength (a) Ti-48Al, (b) Ti-48Al-2Nb, (c) Ti-48Al-2Nb-0.7Cr), and (d) Ti-48Al-2Nb-0.7Cr-0.3Si alloys, and river patterns in all the alloys (c-f) 


\section{Deformation and fracture behaviour of the $\gamma$-TiAl based intermetallic alloys}

of the four alloys. Infrequent interlamellar fractures and few facets are evident in these alloys. The fracture, comprising more facets/irregularities, suggests lower plasticity, which may indicate the brittleness of the alloy, resulting in improved tensile strength. Furthermore, the fracture surfaces of all specimens, including the ternary and quinary alloys, display features such as river-like patterns characteristic of cleavage fracture (Wang et al., 2017) shown in Figures 4c-f. The cleavage/translamellar fracture originates at the particular crystallographic plane and proceeds at a rapid rate (Wang et al., 2017). A cleavage facet is a crystallographic plane with the lowest surface energy (Wang et al., 2017).

In polycrystalline metals, the low-index crystallographic planes are typically not parallel, whereas when the cracks propagate cleavage steps are generated across the grains, while the river-like patterns are the top view of the cleavage steps (Wang et al., 2017). The 'river' patterns commence from the grain boundary flaws and terminate at the grain boundary of the same grain. Therefore, cracks originated inside the specimens. Additionally, secondary cracking at lamellar interfaces at room temperature is often observed in the ternary and the quinary alloy, as illustrated in Figures $5 \mathrm{a}$ and $5 \mathrm{~b}$. The cracks began at the grain boundary and extended by interlamellar propagation. The arrows indicate interlamellar secondary cracking. Secondary crack branching, which propagated along lamellar interfaces (which is the path of least resistance), indicates that the lamellar structure of the alloys exhibited robust resistance to translamellar fracture. Consequently, the ternary and quinary alloys had higher tensile strength than the binary and the quaternary alloys.

Figures 6a-d show optical micrographs of the side views of the fractured alloy samples to further validate the fracture analysis results. The fracture zone near the surface was observed for the four alloys investigated. The microcracks are caused by the presence of the $\beta$-phase for binary, ternary, and quaternary alloys (Figures 6a-c), while for the quinary alloy (Figure 6d) the $\mathrm{Ti}_{5} \mathrm{Si}_{3}$ phase acted as a crack initiation site. These cracks were initiated along the boundaries between $\gamma$-grains, at the triple junctions of colonies/grains and $\gamma$-grains/lamellar colonies (Chen et al., 2004).

In addition, the crack opening distance and length of the microcracks suggest that the grain boundaries between equiaxed $\gamma$-grains and lamellar colonies act as potential sites for crack initiation. However, when the main crack stops at the grain boundary barrier, a new crack can start along the lamellar interface at the rear end of the grain barrier. This occurs when a lamella within a grain is inclined at a large angle or perpendicular to the crack propagation plane, whereby the resulting crack is averted to delamination mode (Figures 6a-c) (Chen et al., 2004).

The fracture behaviour indicated that the $\beta$-phase is brittle at room temperature. According to Hamza, Kanniah, and Harun (2009) this is due to the limited number of dislocations. The cleavage-like fracture surfaces of the studied $\gamma$-TiAl alloys subsequent to room-temperature tensile tests show the brittle characteristics of the $\beta$-phase. On the one hand, the character of the $\beta$-phase has a significant beneficial effect on the mechanical properties at the intermediate $\left(600-700^{\circ} \mathrm{C}\right)$ operating temperatures of low-pressure turbine blades, for example.

\section{Conclusions}

The deformation and fracture behaviour of $\gamma$-TiAl-based alloys were investigated and the following conclusions were drawn.

> Microstructural examination indicated that all the alloys are comprised of lamellar structures $\left(\alpha_{2}+\gamma\right)$ embedded in columnar dendritic cores in the as-cast condition. However, the quinary alloy exhibited the $\mathrm{Ti}_{5} \mathrm{Si}_{3}$ second phase.

- The binary and quaternary alloys showed more facets, on the fracture surfaces suggesting lower plasticity, which is an indication of the brittleness of the alloy and in turn corresponds to a lower tensile strength.

$>$ Infrequent interlamellar fracture and few facets were evident in the alloys. The lamellar structure of the ternary and quinary alloys exhibited better strength against translamellar fracture, confirmed by the higher tensile strength of these alloys.

> The fracture behaviour, viz. the cleavage-like fracture surfaces of the studied $\gamma$-TiAl alloys subsequent to room temperature tensile testing, shows the brittle characteristics of the $\beta$-phase.

\section{Acknowledgement}

The authors thank the Department of Science and Technology (DST) and the CSIR for funding this work.

\section{References}

Chen, J.H., Wang, G.Z., CAo, R., and Zhang, J. 2004. Study on notch fracture of TiAl alloys at room temperature. Metallurgical Transactions A., vol. 35. pp. 439-456.

Grytsiv, A., Rogl, P., Giester, G., and Pomjakushin, V. 2005. Crystal chemistry of the G-phase region in the Ti-Co-Al system. Interrmetallics, vol. 13. pp. 497-509.

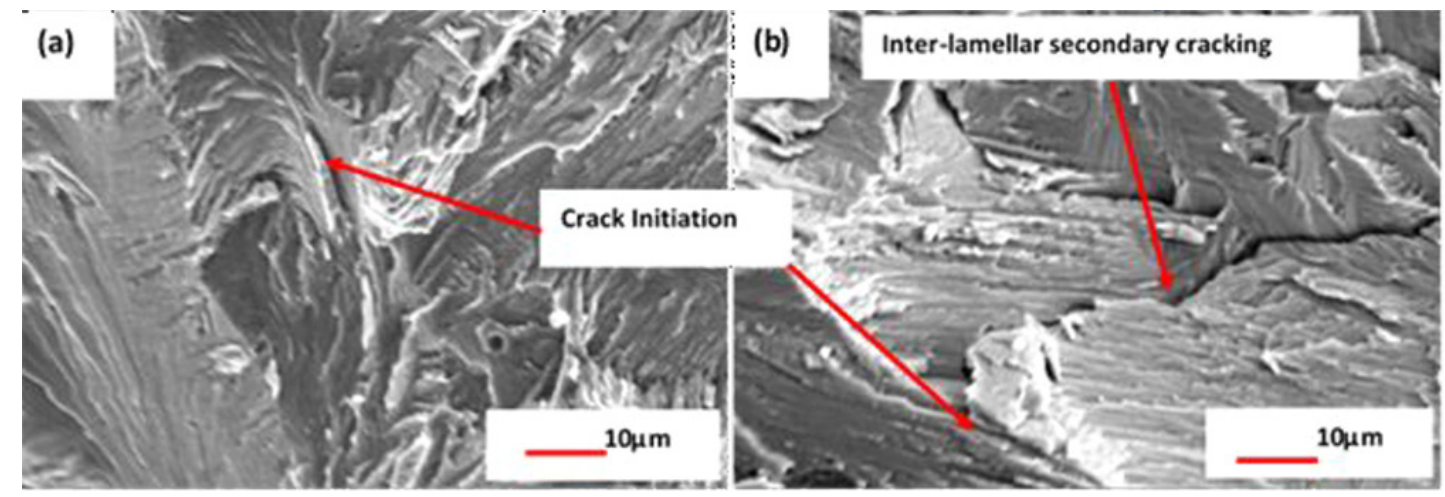

Figure 5-Translamellar fracture with secondary cracking in (a) Ti-48Al-2Nb and (b) Ti-48Al-2Nb-0.7Cr-0.3Si alloys 


\section{Deformation and fracture behaviour of the $\gamma$-TiAl based intermetallic alloys}
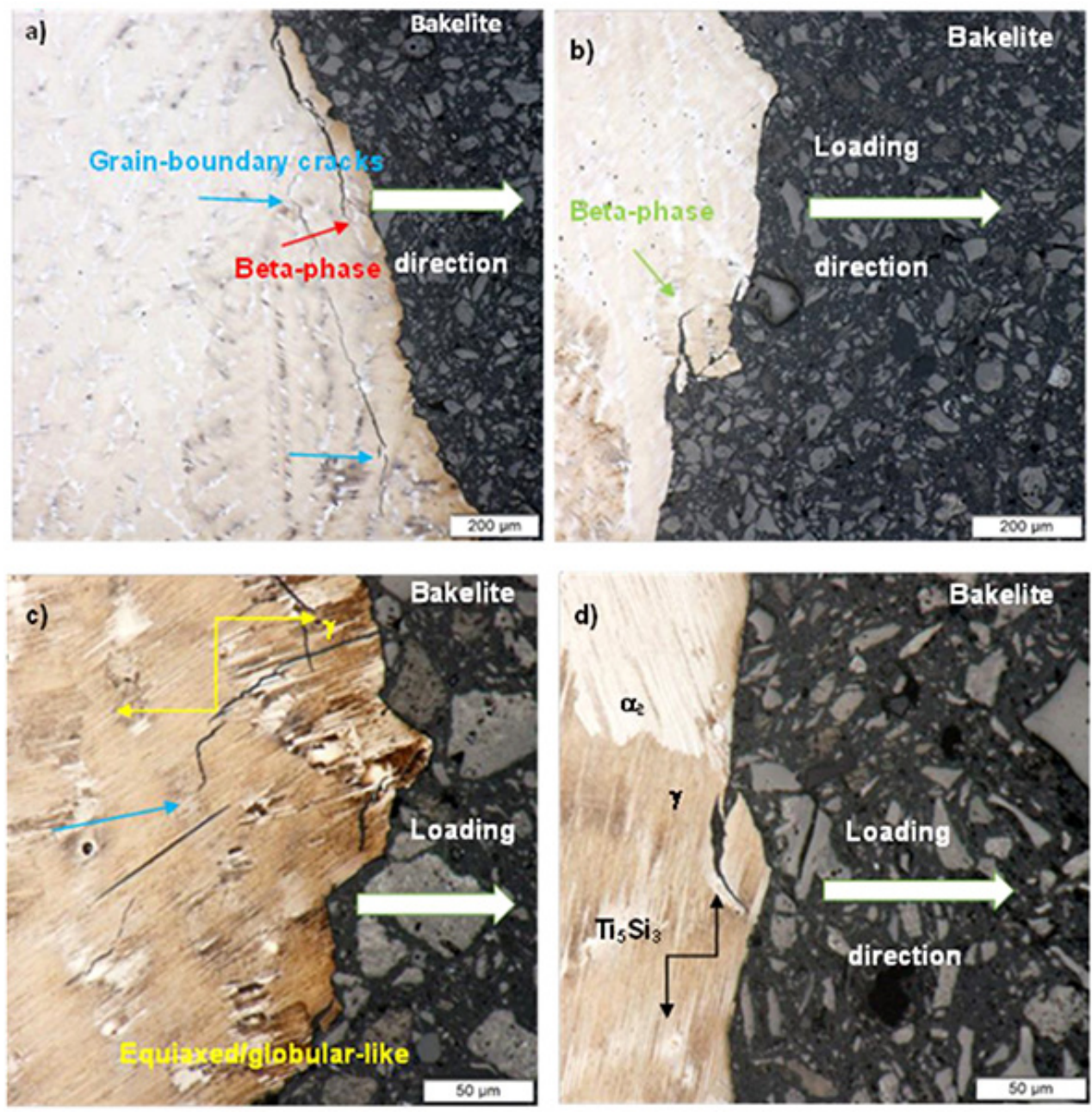

Figure 6-Optical micrographs taken near the fractured surface with subsequent room temperature tensile failure of (a) Ti-48Al, (b) Ti-48Al-2Nb, (c) Ti-48Al-2Nb$0.7 \mathrm{Cr}$ ), and (d) Ti-48Al-2Nb-0.7Cr-0.3Si alloys

Hamzah, E., Kanniah, M., and Harun, M. 2009. Effect of beta phase on room Variations of microstructure on room to high temperature mechanical properties of as-cast gamma titanium aluminide. Mechanics of Advanced Materials and Structures, vol.16. pp.384-389.

Huang, S. and Hall, E.L. 1991. The effects of Cr additions to binary TiAI-base alloys. Metallurgical Transactions A., vol. 22. pp. 2619-2625.

Kabir, M.R., Bartsch, M., Chernova, L., Kelm, K., and WischeK, J.A. 2015. Correlations between microstructure and room temperature tensile behavior of a duplex TNB alloy for systematically heat treated samples. Materials Science and Engineering A., vol. 635. pp. 13-22.

Kumaran, S., Sasikumar, T., Arockiakumar, R., and Srinivasa Rao, T. 2008. Nanostructured titanium aluminides prepared by mechanical alloying and subsequent thermal treatment. Powder Technology, vol. 185. pp. 124-130.

LipsitT, H.A., Shechtman, D., and Schafrik, R.E 1980. The deformation and fracture of Ti3Al at elevated temperature. Metallurgical Transactions A., vol. 11. pp. 1369-1375.

Liu, T., Luo, L.S., Zhang, D.H., WAng, L., Li, X.Z., Chen, R.R., Su, Y.Q., Guo, J.J., and Fu, H.Z. 2016. Comparison of microstructures and mechanical properties of ascast and directionally solidified Ti-47Al-1W-0.5Si alloy. Journal of Alloys and Compounds, vol. 682. pp. 663-671.

Liu, L.X., Shang, S.L., Hu, Y.J., Wang, Y., Du, Y., and Liu, Z.K. 2017. Insight into $\gamma$-Ni/ $\gamma^{\prime}-\mathrm{Ni} 3 \mathrm{Al}$ interfacial energy affected by alloying elements. Materials \& Design, vol. 133. pp. 39-46.
Mathabathe, M.N., Govender, S., Bolokang, A.S., Mostert, R.J., and Siyasiya, C.W. 2018a. Phase transformation and microstructural control of the $\alpha$-solidifying $\gamma$ -Ti-45Al-2Nb-0.7Cr-0.3Si intermetallic alloy. Journal of Alloys and Compounds, vol. 757 . pp. 8-15.

Mathabathe, M.N., Bolokang, A.S., Govender, G., Mostert, R.J., and Siyasiya, C.W. 2018b. The vacuum melted $\gamma$-TiAl (Nb, Cr, Si)-doped alloys and their cyclic oxidation properties. Vacuum, vol. 154. pp. 82-89.

Mathabathe, M.N., Bolokang, A.S., Govender, G., Siyasiya, C.W., and Mostert, R.J. 2019a. Cold-pressing and vacuum arc melting of $\gamma$-TiAl based alloys. Advances in Powder Technology, vol. 30. pp. 2925-2939.

Mathabathe, M.N., Govender, G., Siyasiya, C.W., Mostert, R.J., and Bolokang, A.S 2019b. Surface characterization of the cyclically oxidized $\gamma-\mathrm{Ti}-48 \mathrm{Al}-2 \mathrm{Nb}-0.7 \mathrm{Cr}$ alloy after nitridation. Materials Characterization, vol. 154. pp. 94-102.

Sun, F. and Froes, F.H.S. 2002. Precipitation of Ti 5 Si3 phase in TiAl alloys. Matererials. Science and Engineering A., vol. 328. pp. 113-121.

WANG, Y., Liu, Y., YAng, G.Y., and TAng, B. 2011. Microstructure of cast gamma-TiAl based alloy solidified from bata phase region. Transactions of the Nonferrous Metals Society of China, vol. 21. pp. 215-222.

Wang, Q., Ding, H., Zhang, H., Chen, R., Guo, J., and Fu, H.A. 2017. Variations of microstructure and tensile property of $\gamma$-TiAl alloys with 0-0.5 at\% $\mathrm{C}$ additives. Materials Science and Engineering A., vol. 700. pp. 198-208.

Yan, X., Grytsiv, A., Rogl, P., Schmidth, H.,Giester, G., Saccone, A., and Chen, X-Q. 2009. Laves phases in the ternary systems Ti- $\{\mathrm{Pd}, \mathrm{Pt}\}-\mathrm{Al}$. Intermetallics., vol. 17. pp. 336-342. 